\title{
NASA's APPLIED SCIENCES FOR WATER RESOURCES
}

\author{
Bradley Doorn ${ }^{1}$, David Toll ${ }^{2}$ and Ted Engman ${ }^{3 *}$ \\ ${ }^{* 1}$ Water Resources Applied Sciences Program, NASA Earth Sciences Division, \\ Washington DC 20546, PH: 202-358-2187, Fax: 202-358-3098, \\ Bradley.Doorn@nasa.gov; ${ }^{2}$ Hydrological Sciences Branch, Goddard Space Flight \\ Center, NASA, Greenbelt, MD 20771, PH: 310-614-5801, Fax: 301-614-5808, \\ David.L.Toll@nasa.gov; ${ }^{3}$ Science Applications International Corp., Greenbelt MD \\ 20771, PH: 301-614-5772, Fax: 301-614-5808, Edwin.T.Engman@nasa.gov.
}

\begin{abstract}
The Earth Systems Division within NASA has the primary responsibility for the Earth Science Applied Science Program and the objective to accelerate the use of NASA science results in applications to help solve problems important to society and the economy. The primary goal of the Earth Science Applied Science Program is to improve future and current operational systems by infusing them with scientific knowledge of the Earth system gained through space-based observation, assimilation of new observations, and development and deployment of enabling technologies, systems, and capabilities. This paper discusses one of the major problems facing water resources managers, that of having timely and accurate data to drive their decision support tools. It then describes how NASA's science and space based satellites may be used to overcome this problem. Opportunities for the water resources community to participate in NASA's Water Resources Applications Program are described.
\end{abstract}

\section{INTRODUCTION}

Viewed from above (figure 1), our home planet stands out as a "blue marble" set against the vast blackness of outer space, with an abundance of water on its surface. Yet, only a small portion of this water is fresh and available for consumption by plants, animals and humans. One only has to look at the land surfaces to understand the regional differences in the distribution of water on a global context. Lush green areas reflect regions of adequate water resources and yellow-brown regions indicative of perpetual water shortages.

The total amount of water on Earth has remained unchanged for literally millions of years. While the amounts in various phases has changed due to glacial formation and melting, the total of all phases has not changed. How much are we talking about and how much of that is available for sustenance of human life? 


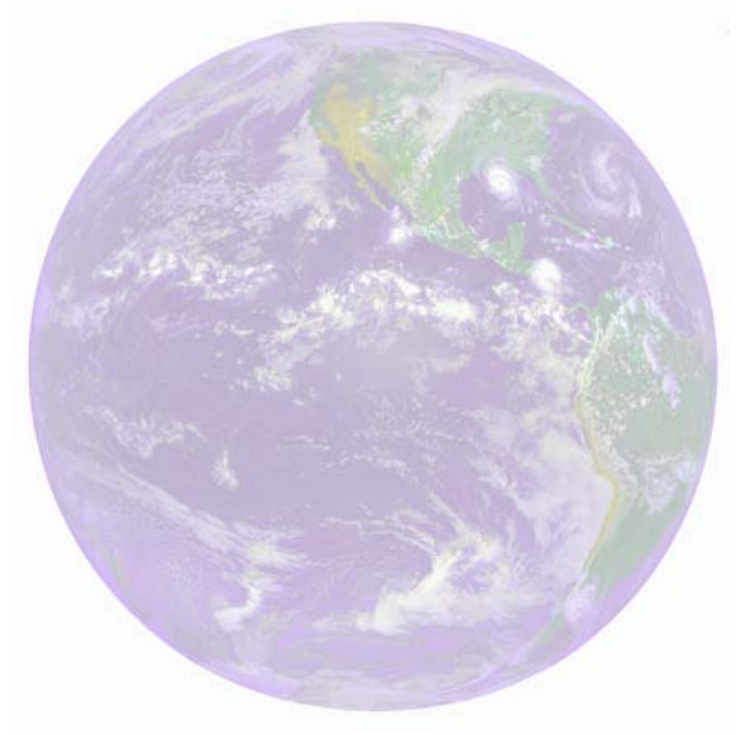

Figure 1. The "blue" planet as seen from space.

Unfortunately, most of the world's water has little potential for human use because it is salt water, approximately 97.5 percent. This leaves us with just 2.5 percent of the world's water being potentially useful for humans, but most of this is locked up in ice sheets at the poles. The fresh water accessible to humans amounts to a paltry 0.26 percent of the total available water. Yet, on the average this is a fairly significant amount. The problem is that the average, both in time and space exists in very few places on the globe. Even in the ideal world the natural variations in the hydrologic cycle from day to day and place to place result in huge discrepancies of available water. In addition human impacts on the hydrologic cycle can be dramatic and increases in the global population have put major constraints on available fresh water supplies. For example, the global runoff per capita in 1970 was (on the average) 12,900 cubic meters per person. By 1995, this had decreased to 7,600 cubic meters per person due to increases in the global population. Still, this is a lot of water, but it is the global average, and not the amount available where the population pressures are the greatest.

\section{SUSTAINABILE WATER RESOURCES}

The first step in developing a water resources sustainability strategy and management plan is to know the quantity and quality of water available. Water resources assessment is a necessary step if one is to develop societal benefits such as domestic and industrial water supplies, maintenance of human health, hydropower, irrigation, flood protection, droughts, navigation, recreation and preservation of the environment. This is not a trivial task even in data rich regions of the world, but in data sparse regions it becomes almost impossible. One has to start with adequate reliable hydrologic data on the quantity and the quality of the available water 
resources. One must then account for modifications in the hydrology brought about by human uses, agriculture, manufacturing and pollution control. For many regions of the world, and particularly in the developing world, these data do not exist or are unreliable. Embarking on a data collection campaign with traditional methods and instrumentation is extremely expensive and requires a large supporting infrastructure.

There are a number of U.S. water agencies (i.e., NOAA, US Army Corps of Engineers, Bureau of Reclamation, National Resources Conservation Service, etc.) as well as private engineering and consulting firms that have a mandate for predicting the flow rate (or depth) of streamflow resulting from rainfall. These predictions are used for real time river management (flood forecasting, water supply, navigation, minimal flow rates for ecological requirements) as well as for design of engineering structures (dams, bridges and culverts, channel protection and levees, etc) and non-structural methods such as flood plain zoning. In addition to the U.S. water agencies, there are numerous universities with civil engineering, agricultural engineering or hydrology departments that are working to develop and improve water resource prediction models and Decision Support Tools (DST).

What this boils down to is that there are a plethora of models and decision support systems available to predict streamflow. All (or almost all) are capable of providing accurate predictions of streamflow if used for conditions for which they were developed and there is adequate and accurate input data to drive the models and DSTs

\section{A SATELLITE HYDROLOGY SOLUTION}

Monitoring the surface and ground water supply is a vital societal need. Surface water includes both flowing water in streams and rivers, natural lakes, polar ice caps and man-made reservoirs. Ground water includes the large amounts of water stored beneath the Earth's surface in aquifers - vitally important to the viability of agriculture in arid climates. It is important to determine where supplies of fresh water are located, to quantify how much water is available, and to figure out if and how rapidly the water supply is increasing or decreasing. Increased demand threatens to deplete these precious water resources and accurate information on water availability is needed to meet the water resource needs of ever growing populations.

The major space agencies of the world and their partnering meteorological services maintain a vast array of Earth observing satellites capable of providing basic measurement hydrological data, weather, climate, land use, water use and diversions, and natural and human-induced hazards. Data collected and information created from Earth observations have the potential for providing critical inputs to sustainable water resources development and management. These Earth observations also 


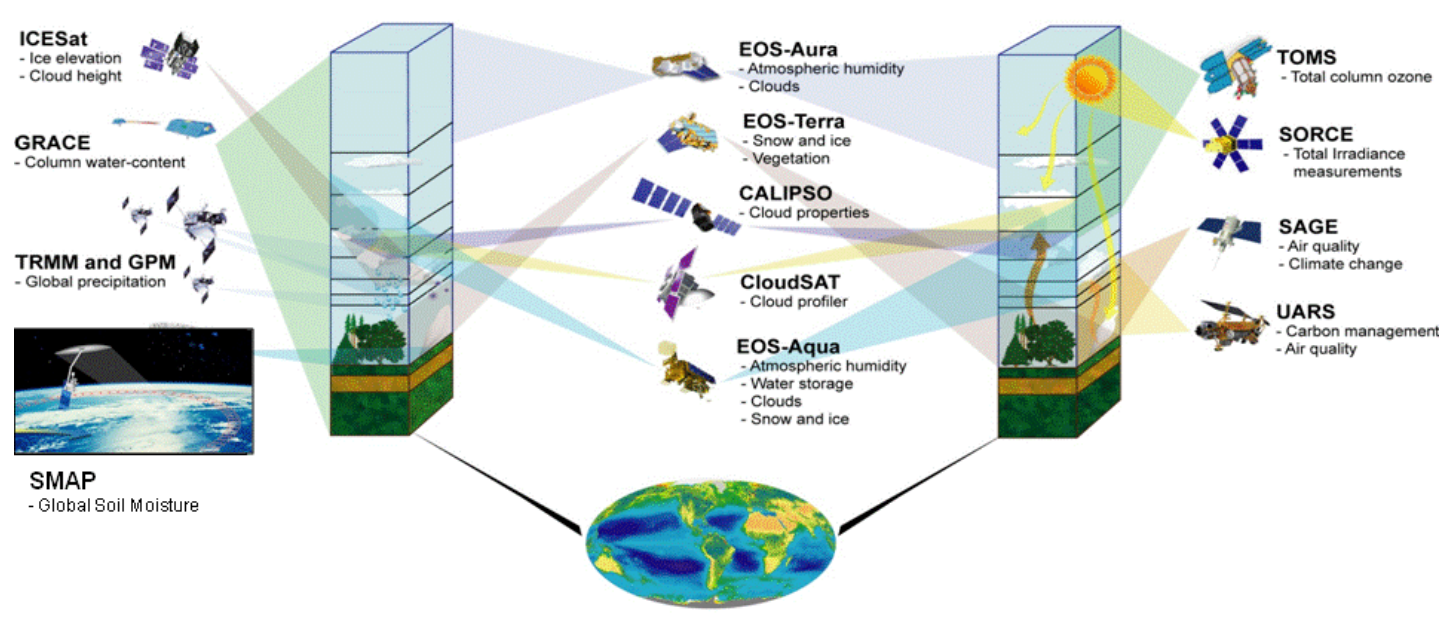

Complementary Water and Energy Cycle Missions

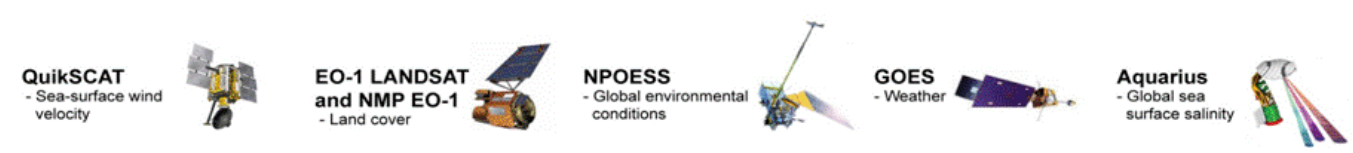

Figure 2. NASA missions for water resources assessment and management.

provide information for informed decision making and for monitoring conditions and progress at multiple special and temporal scales. Figure 2 illustrates NASA's fleet of satellites that are able to provide important measurements of the hydrologic cycle that can be used for water resources assessment and management in regions of the world where traditional data are insufficient or nonexistent.

\section{NASA's MISSION}

The NASA vision and mission statements include a clear focus on the Earth and life on Earth. NASA seeks to improve life on Earth by enabling people to use measurements of our home planet in valuable ways. NASA's Earth Science Division has primary responsibility for two Agency-wide, Earth oriented themes in the NASA strategic plan: Earth system science and Earth science applications. In serving these themes, the division works with its domestic and international partners to provide accurate, objective scientific data and analysis to advance our understanding of Earth system processes and to help policy makers and citizens achieve economic growth and effective, responsible stewardship of Earth's resources.

NASA has long been considered to be a science organization but only within the last few years has its Applied Science Program begun to have an impact of the solving of the nations technical, societal and economic problems. The Earth Systems Division within NASA has the primary responsibility for the Earth Science Applied Science Program and the objective to accelerate the use of NASA science results in applications to help solve problems important to society and the economy. 


\section{NASA's APPLIED SCIENCES PROGRAM}

NASA's Applied Science Program has identified seven priority national applications (program elements) of which water resources is one. NASA collaborates with partner organizations to enable and enhance the application of NASA's Earth system science results to serve national priority policy and management Decision Support Systems (DSS) and Decision Support Tools (DSTs). The Water Resources Program Element addresses issues of concern and decisionmaking related to water quality and availability. Some cross-cutting activities also relate to the Weather, Agricultural, Natural Disasters, Public Health and Ecological Forecasting program Elements. The Water Resources Program Element extends NASA research results to decision support tools that address issues related to water availability and quality: The desired outcome is for partner organizations to use project results, such as prototypes and benchmark reports, to enable expanded use of Earth science data and products to enhance their decision-support capabilities.

\section{THE INTEGRATED SYSTEMS SOLUTION ARCHITECTURE}

Figure 3 illustrates the architecture underlying the Earth Science Applications Program. To the right, partner agencies and organizations own, develop, and operate Decision Support Tools (DSTs) to analyze scenarios, identify alternatives, assess

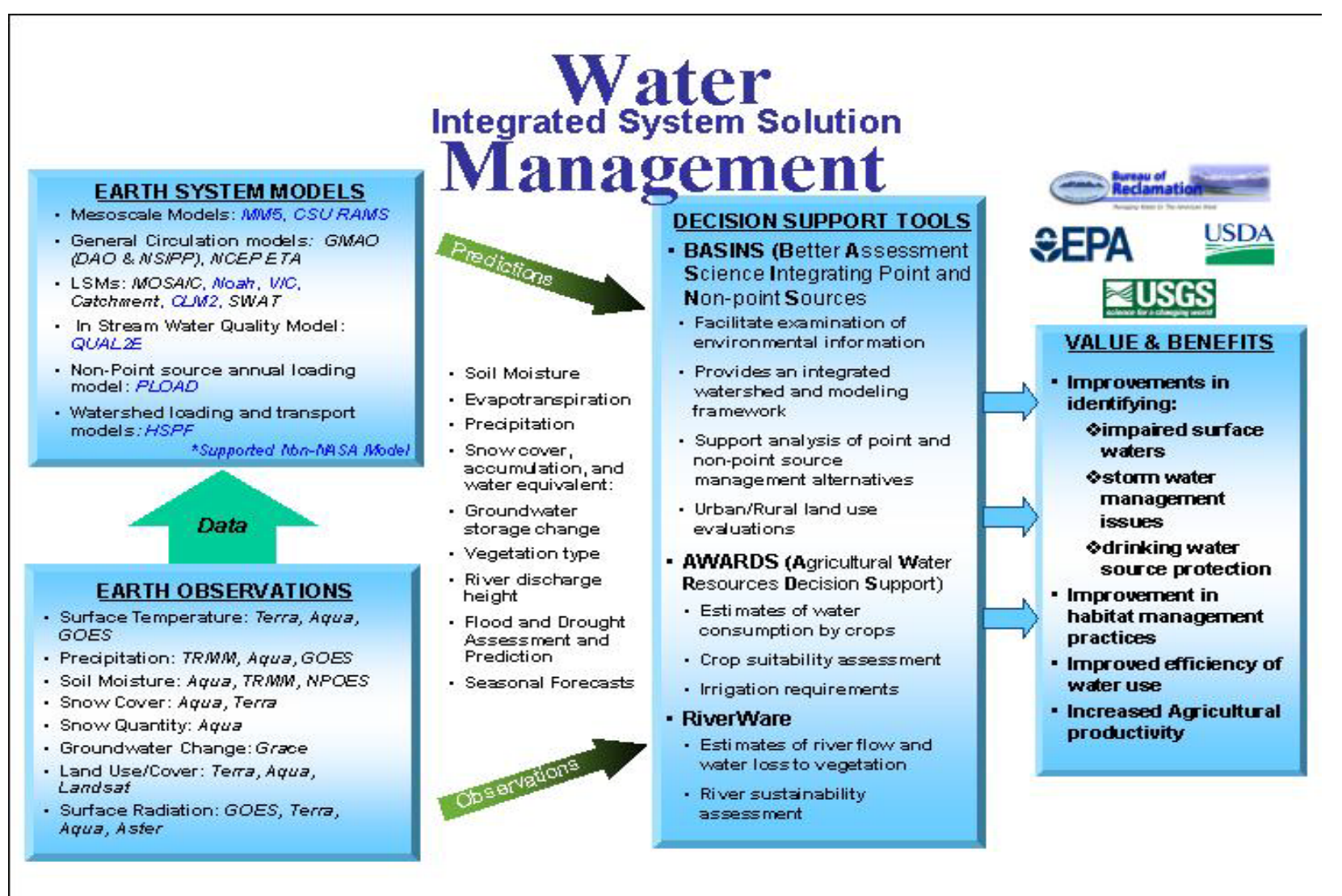

Figure 3. Example of a water resources Integrated Systems Solutions architecture. 
risks, to implement their decision making process. Federal agencies use these DSTs to support their responsibilities for efficient and effective water management. On the left side of the figure, NASA, as a research and development agency, extends its observations (data), model products and predictions, and computational techniques from its Earth science research to support its partners. Where the Earth science products have been determined to have potential value, NASA and its partners will collaborate to facilitate and streamline the flow of products to the DSTs (middle region of the figure), drawing on interoperability practices to support data system and system integration.

\section{THE WATER RESOURCES GOAL}

The goal of the Water Resources Program is to enable partners' beneficial use of NASA Earth-Sun System science observations, models, and technology to enhance decision support capabilities serving their water management and policy responsibilities. Major tenets of the Water Management Program goal include:

- Develop and nurture partnerships with appropriate water management organizations

- Identify and assess partners’ water management responsibilities, plans, and decision support tools and evaluate capacity of NASA Earth system science results to support the partners

- Validate and verify application of NASA Earth system science results with the partners' DSSs

- With partners, document value of Earth system science results relative to partners' obligations and support adoption into operational use

- Communicate results and partners' achievements to appropriate water communities and stakeholders

\section{NASA'S EARTH SCIENCE CONTRIBUTIONS.}

The Water Resources Program extends products derived from Earth science information, models, technology, and other capabilities into partners' decision support tools for water management issues. NASA partners with Federal agencies and other organizations that have water management responsibilities and mandates to support water resource managers. Partnerships with the U.S. Environmental Protection Agency (EPA), Department of Interior Bureau of Reclamation (BoR), the National Oceanic and Atmospheric Administration (NOAA), US Agency for International Development, the Department of Agriculture (USDA) and numerous state, university, private and non-government groups have been established.

For the water resources program element, NASA data and data products have the potential to impact partner's DSTs in the following general ways:

- Estimating water storage - snowpack, soil moisture, and aquifers. 
- Modeling and predicting water fluxes - evapotranspiration, precipitation, river runoff.

- Monitoring water quality - turbidity, eutrophication, temperature

Measurements from sensors on Earth Science missions for the Water Resources Program Element include current programs such as Aqua, Terra, Grace, TRMM (Tropical Rainfall Measurement Mission), EO-1 (Earth Observing-1, Landsat. For example, the Moderate Resolution Imaging Spectroradiometer (MODIS) and the Clouds and the Earth's Radiant Energy System (CERES) instruments on the Terra and Aqua spacecraft are helping to refine our estimates of surface energy balance at the surface, which helps to improve our understanding of evaporation over the Earth's surface. The Advanced Microwave Scanning Radiometer for EOS (AMSR-E) on Aqua is refining our ability to track changes in surface soil moisture and to represent these processes in atmospheric models. The Tropical Rainfall Measuring Mission (TRMM) monitors tropical/subtropical precipitation patterns. Figure 4 illustrates the dramatic capabilities possible from space based measuring systems. The Gravity Recovery And Climate Experiment (GRACE) allows us to track changes in water storage beneath the surface. Supplemented by other information, this should allow us to monitor aquifer water storage changes from space. The Global Precipitation Measurement (GPM) mission,

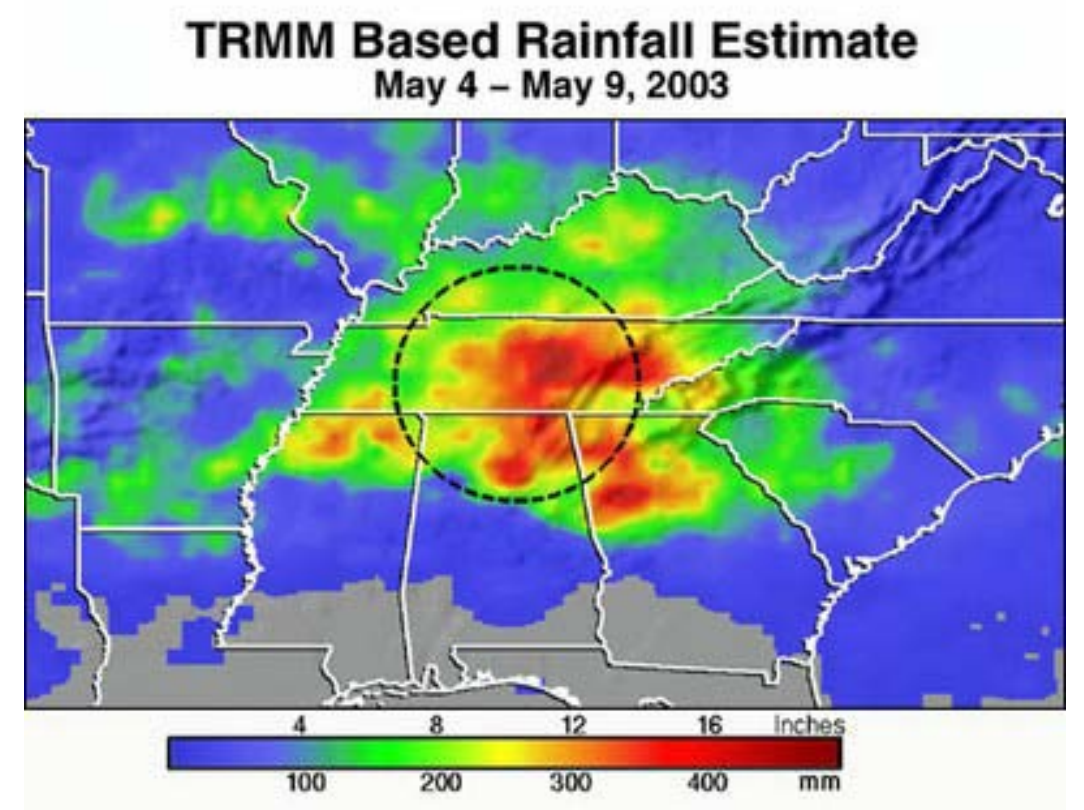

Figure 4: Data from TRMM and other satellites estimated more than 16 inches of rain fell in the red areas of the top map (TN, AL, GA) from May 4-9, 2003 from spring storms. Credit: Hal Pierce/Jeff Halverson, NASA Goddard Space Flight Center. 
a successor to TRMM, and National Polar-orbiting Operational Environmental Satellite System (NPOESS)--missions planned for later this decade--will lead to steady improvements in water quantity assessments. Landsat 7 and the Hyperion instrument on Earth Observing-1 (EO-1) obtain visual images of sections of the Earth that can be analyzed to track changes in water quality over time. The Landsat Data Continuity Mission (LDCM), a joint NASA/U.S. Geological Survey (USGS) mission, will continue the long-running Landsat data record, and enhance our capabilities to remotely sense water quality in the coming years.

Incorporating all of this information into decision support systems will lead to improved capability to predict water availability, protect water quality, and plan for water conservation. Many agencies, including the U.S. Department of Interior's Bureau of Reclamation (BoR), the Environmental Protection Agency (EPA) and the U.S. Department of Agriculture (USDA), should benefit from these improvements to decision tools used for water management.

\section{EXAMPLES OF NASA APPLICATIONS}

The following list provides a brief description of the scope and depth of applied sciences projects being funded by NASA's Applied Sciences Program in the field of water resources. Details on any one of these can be found in the Program web site: http://wmp.gsfc.nasa.gov

- $\quad$ "Developing Seasonal Predictive Capability for Drought Mitigation Decision Support System"

- $\quad$ "Improving Water Supply Forecasts in the Western U.S. Using NASA Earth Science Results"

- $\quad$ "Improving water resources management in the Western US through use of remote sensing data and seasonal climate forecasts"

- "Enhancing Water Management Decision Support Systems with High SpatioTemporal Resolution Mapping of Actual Evapotranspiration"

- "Improving water resources management in the Western US through use of remote sensing data and seasonal climate forecasts"

- $\quad$ "National Drought Monitoring System for Drought Early Warning Using Hydrologic and Ecologic Observations from NASA Satellite Data"

- "Development of a Robust Drought Index for Agricultural Applications"

- $\quad$ "Introducing Remotely Sensed Irrigation Information into the USDA FAS Decision Support System"

- $\quad$ "Integrating Enhanced GRACE Water Storage into the U.S. and North American Drought Monitors"

- $\quad$ "Benchmarking NASA Snow Research Results in NWS Hydrological Decision Support"

- $\quad$ "Developing Seasonal Predictive Capability for Drought Mitigation Decisions Support System"

- $\quad$ "Developing Seasonal Predictive Capability for Drought Mitigation Decisions Support System" 
"Improving Water Quality Management: Use of Earth Observations in SPARROW"

\section{FUTURE THRUSTS}

In the future, the Water Resources Program's priorities focus on evolving products for DSTs as well as expanding the variety of measurements and model products to be tested for use in these and other water management decision support tools. Also, potential products of planned satellites (e.g. GPM, Cold Land Processes, WaTER and SMAP, a soil moisture mission) need to be evaluated for their potential to augment current and future DSTs. Potential future observational spacecraft products should be evaluated for both direct use within DSTs, and for indirect use through modeling to improve model output that is used by DSTs. The roadmap illustrated in Figure 5 is an example of how the program may evolve over the next

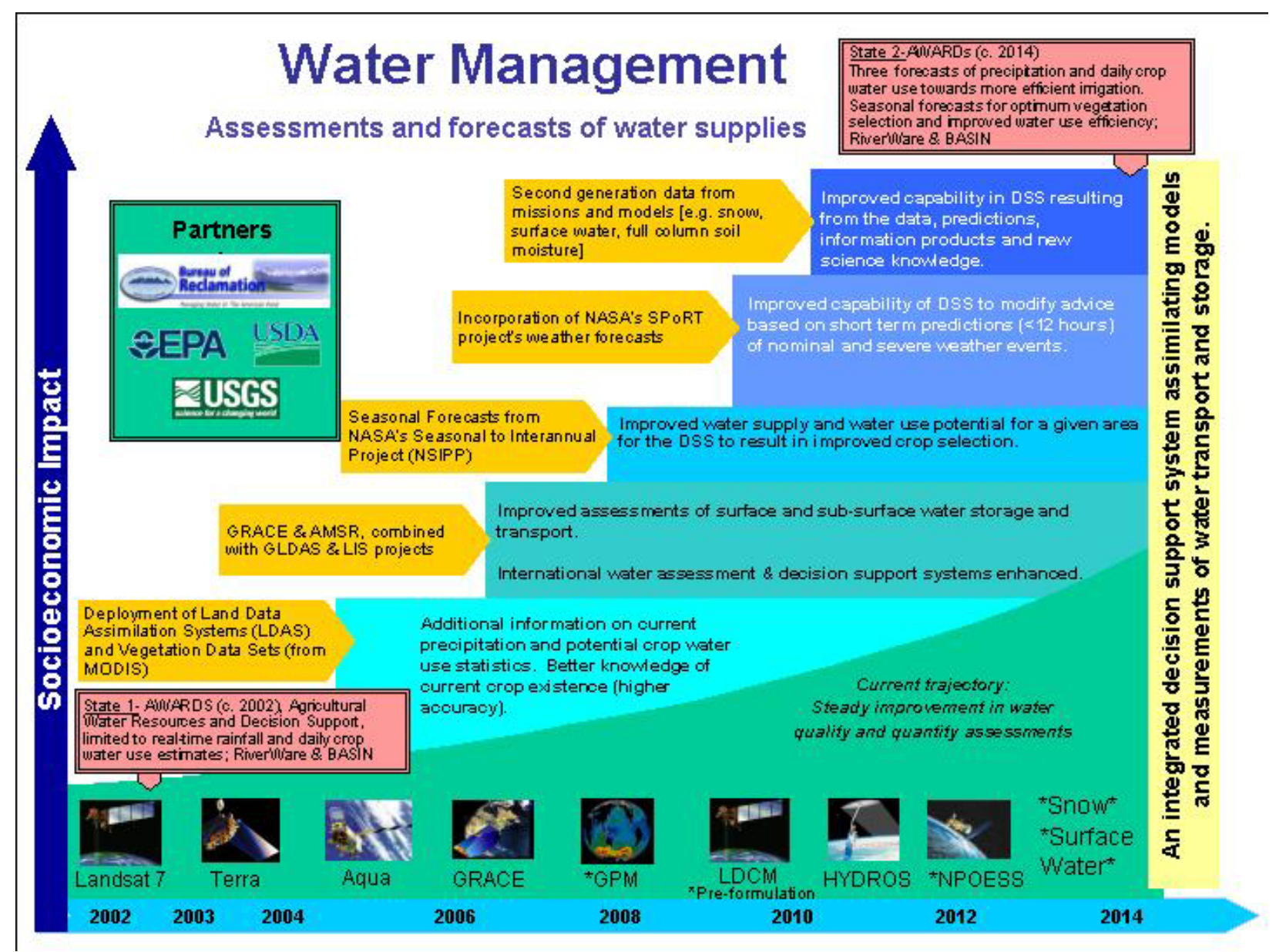

Figure 5. The Water Management Program Element Roadmap using the Bureau of Reclamation's AWARDS DST as an example. 
several years. It illustrates the current state of Water Resources DSTs and the projected state of those DSTs with the infusion of NASA Earth-Sun system science research results.

\section{SUMMARY}

The Water Resources Program leverages appropriate activities, expertise, and assets selected through solicitations and research announcements to serve the program element's objectives. For proposals selected through solicitations funded by the Applied Sciences Program, the Water Resources Program may provide supplemental funding. In addition, the program element may provide funds to projects selected or identified through other Science Mission Directorate solicitations. The program and project managers facilitate appropriate partnerships between solicitation recipients and NASA partners. The activities are carried out through competitive grants that are peer reviewed to insure that they are technically feasible and address high priority Program goals. Governmental, private and academic organizations are encouraged to participate and compete for NASA support to enhance their problem solving mandates.

The following are useful web sites for those that want more details about the Applied Sciences Water Management Program or are interested in submitting proposals for support.

Information on NASA research opportunities can be found at;

http://nspires.nasaprs.com/external/

This site has general information about Earth sciences and applications:

http://www.earth.nasa.gov

This site describes NASA’s Applied Sciences Program:

http://science.hq.nasa.gov/earth-sun/applications/index.html

This site describes the Water Resources projects:

http://wmp.gsfc.nasa.gov 